\title{
Status of Rifaximin: A Review of Characteristics, Uses and Analytical Methods
}

\section{Ana Carolina Kogawa \& Hérida Regina Nunes Salgado}

To cite this article: Ana Carolina Kogawa \& Hérida Regina Nunes Salgado (2018) Status of Rifaximin: A Review of Characteristics, Uses and Analytical Methods, Critical Reviews in Analytical Chemistry, 48:6, 459-466, DOI: 10.1080/10408347.2018.1447355

To link to this article: https://doi.org/10.1080/10408347.2018.1447355

曲 Published online: 26 Mar 2018.

Submit your article to this journal

Џlll Article views: 199

Citing articles: 1 View citing articles $\sqsubset$ 


\title{
Status of Rifaximin: A Review of Characteristics, Uses and Analytical Methods
}

\author{
Ana Carolina Kogawa (D) and Hérida Regina Nunes Salgado (D) \\ São Paulo State University (UNESP), School of Pharmaceutical Sciences, Campus Araraquara, Araraquara, São Paulo, Brazil
}

\begin{abstract}
Rifaximin, an oral antimicrobial, has many advantages because it is selective intestine, has minimal adverse effects and is used for the treatment of some diseases such as hepatic encephalopathy, irritable bowel syndrome, travelers' diarrhea, ulcerative colitis, Clostridium difficile and acute diarrhea. Rifaximin in the form of $200 \mathrm{mg}$ tablets is commercially available. The crystalline $\alpha$ form is therapeutically safe and effective. In most of the official compendia, rifaximin has no monograph and in none of them is there a monograph for rifaximin tablets. The literature, however, contemplates this gap with varied methods. The literature presents some methods for evaluation of rifaximin in both biological fluid and pharmaceutical product. High performance liquid chromatography stands out for the evaluation of rifaximin. Most of the methods reported in the literature are for pharmaceuticals products. They use (1) toxic organic solvents, harmful to the operator and the environment, and/or (2) buffer solution, which has a shorter service life and requires time-consuming washes of the chromatographic system generating more waste. So, this work aims to discuss (i) properties; (ii) applications; (iii) polymorphism and (iv) analytical methods of rifaximin by the look of green chemistry. This review shows an extremely current topic of great importance to the chemical-pharmaceutical area and everything it involves, since the analytical process until the impact on the environment in which it is embedded.
\end{abstract}

\section{KEYWORDS}

Analytical methods; antimicrobial; green chemistry; HPLC;

polymorphism; rifaximin

\section{Introduction}

Rifaximin is an oral antimicrobial with broad spectrum of action non-absorbable. It acts in the gastrointestinal tract and presents minimal adverse effects. ${ }^{[1,2]}$ It is practically not absorbed and achieves high concentrations in the human intestine, where it is active against many enteropathogens. $^{[3]}$

It is a non-systemic antimicrobial derived from rifamycin. ${ }^{[4]}$ Its high tolerability can be compared to placebo. ${ }^{[2,5]}$ It is used safely for the treatment of many different diseases by children, the elderly and debilitated people. Thus, rifaximin reaches a large target audience and therefore analytical methods for the evaluation of its quality must be effective and reliable. However, in the current scenario, they must also be environmentally friendly.

The use of non-toxic reagents, the careful choice of the analytical method as well as the apparatus to be used, the speed of the analysis, the residues generated and the amount of sample used are examples of parameters relevant to green chemistry. Currently, analytical processes must be viewed in a multi-dimensional way and appropriate to the world reality, where there is a growing concern with the health of the environment and everything that surrounds it. ${ }^{[6-9]}$

Therefore, the objective of this review is to discuss about (i) properties, (ii) applications, (iii) polymorphism and (iv) analytical methods of rifaximin by the look of green chemistry.

\section{Rifaximin}

Rifaximin, Figure 1, has structure analogous to rifampicin and is a derivative of rifamycin. Rifampicin and rifabutin are equally effective in tuberculosis schemes for HIV-positive and HIV-negative patients. Rifabutin is more active than rifampicin against Mycobacterium avium, and is preferentially used in multiple drug regimens for these infections, but otherwise rifampicin is the drug of choice. Resistance develops rapidly with rifampicin, so it is rarely used alone.

Rifaximin binds to the $\beta$ subunit of the bacterial enzyme RNA polymerase DNA-dependent and inhibits bacterial RNA synthesis. $^{[2]}$

Rifaximin is used in cases of hepatic encephalopathy, ${ }^{[1-5,10]}$ ulcerative colitis, ${ }^{[10]}$ irritable bowel syndrome, ${ }^{[4,2]}$ Clostridium difficile, ${ }^{[2,3]}$ diarrhea of travelers ${ }^{[2-4,11,12]}$ and acute diarrhea. ${ }^{[13]}$

\section{Hepatic encephalopathy}

Hepatic encephalopathy is a complex liver disease. It is considered as a metabolic disorder or neurophysiological. ${ }^{[10]}$

Normal patients remove nitrogen residues produced by gastrointestinal bacteria. In this process, ammonia is metabolized in urea and excreted. Patients with hepatic encephalopathy cannot convert ammonia to urea and consequently it accumulates in the blood. This generates accumulation in the central nervous system and affects neurotransmission. Hepatic

CONTACT Hérida Regina Nunes Salgado salgadoh@fcfar.unesp.br E São Paulo State University (UNESP), School of Pharmaceutical Sciences, Campus Araraquara, Rodovia Araraquara-Jaú, km 1, 14800-903, Araraquara, São Paulo, Brazil.

Color versions of one or more of the figures in the article can be found online at www.tandfonline.com/batc.

○2018 Taylor \& Francis Group, LLC 


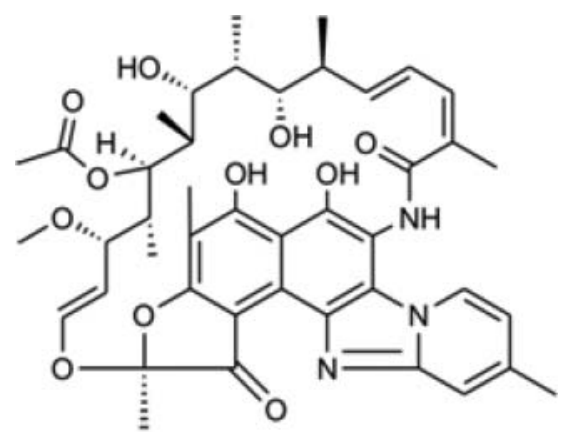

Figure 1. Chemical structure of rifaximin (CAS 80621-81-4, $\mathrm{C}_{43} \mathrm{H}_{51} \mathrm{~N}_{3} \mathrm{O}_{11}$ and molecular weight $785.9 \mathrm{~g} \mathrm{~mol}^{-1}$ ).

encephalopathy is associated with portal hypertension in patients with cirrhosis and chronic liver disease. ${ }^{[2]}$

\section{Treatment}

The neuropsychiatric symptoms and neuromuscular dysfunction associated with hepatic encephalopathy are accounted for the clinical and socioeconomic burden of chronic liver disease for patients and their caregivers. Hepatic encephalopathy often results in hospitalization and decreased survival in patients with cirrhosis. Prevention of hepatic encephalopathy episodes can improve the results for patients while they wait for transplantation and improve post-transplant function. A long-term therapeutic intervention to prevent the recurrence of hepatic encephalopathy is necessary to decrease the burden of health care, enhance quality of life and improve results for patients with chronic diseases. ${ }^{[1]}$

Current strategies as removal of precipitating factors, increase the elimination of ammonia or reduce ammonia production are used for hepatic encephalopathy. For this, lactulose was chosen, but its continued use is problematic and there are patients who do not tolerate or do not respond to therapy with lactulose. ${ }^{[1,2,5]}$ Rifaximin has been an option for this case. ${ }^{[2,5]}$

\section{Irritable bowel syndrome}

Irritable bowel syndrome, a chronic gastrointestinal disease, affects up to $20 \%$ of the general population. The diagnosis is often an exclusion diagnosis. ${ }^{[2]}$

It can be characterized by change in bowel habits, abdominal pain, diarrhea, constipation and swelling. The etiology of irritable bowel syndrome may be due to changes in peripheral and central sensory. ${ }^{[2]}$ In addition to this, data show that there is a relationship between intestinal bacterial overgrowth and irritable bowel syndrome. ${ }^{[2,4]}$ In it the normal intestinal flora of the proximal intestine is altered in quantity and quality; flora adopts the characteristics of large bowel flora of aerobic and anaerobic and aerobic and anaerobic coliform predominate at

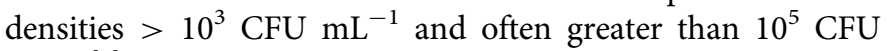
$\mathrm{mL}^{-1} \cdot[4]$

\section{Clostridium difficile}

Rifaximin can be a treatment option for patients with multiple recurrent episodes of $C$. difficile according to the Society for
Healthcare Epidemiology of America (SHEA) and Infectious Diseases Society of America (IDSA). ${ }^{[2,3]}$

\section{Traveler's diarrhea}

Traveler's diarrhea is a disease very common for those returning from tropical areas and it is usually caused by Escherichia coli (enterotoxigenic and enteroaggregative mostly), which may be identified in $50 \%$ of cases ${ }^{[11,12]}$ followed by Shigella spp. The traveler's diarrhea is a self-limited disease and normally treatment with antibiotics is not required, unless the circumstances become worse. ${ }^{[12]}$

\section{Treatment}

The most common treatment for travelers' diarrhea with antibiotics uses fluoroquinolones. However, amoxicillin + clavulanate, azithromycin, erythromycin or cotrimoxazole are often used. $^{[12]}$

Quinolones presents a good activity against traveler's diarrhea pathogens, but they are expensive for some countries. However, currently pathogens causing travelers' diarrhea have been shown to be resistant to quinolones. A reduction in the effectiveness of quinolones highlights the urgency of finding alternative therapies. For example, ciprofloxacin is very effective against E. coli and Shigella sonnei, but it is associated with toxicity and drug interactions. Thus, non-absorbable antibimicrobials should overcome the limitations of the systemic antimicrobials and rifaximin, a derivative of rifamycin characterized by a broad antibacterial spectrum, is an excellent option. ${ }^{[11,12]}$

\section{Acute diarrhea}

Acute diarrhea, severe and fatal in some cases, hits children most of the time. Children with genitourinary malformations or anal dysfunctions often experience diarrhea outbreak due to modification of the normal bacterial flora. ${ }^{[13]}$

\section{Treatment}

Diarrhea frequently occurs in children. Some of them had experience with acute gastroenteritis because they used nitrofurantoin or trimethoprim/sulfamethoxazole to prevent urinary tract infections. Fast antimicrobial treatment of diarrhea episodes in these children is necessary to avoid complications. In this situation, rifaximin is a good choice. It has a wide range of antimicrobial activity, is selective bowel and therefore has minimal adverse effects. ${ }^{[13]}$

\section{Polymorphism}

Rifaximin is marketed in hydrate form, but the environmental conditions may trigger their conversion to the amorphous form. ${ }^{[14]}$ On the market tablets of $200 \mathrm{mg}$ are found. The dose is $600 \mathrm{mg}$ ( 1 tablet 3 times daily) or $800 \mathrm{mg}$ ( 2 tablets 2 times a day).

Rifaximin, an antimicrobial for local action in the gastrointestinal tract, can exist in form of crystals and amorphous. 
Rifaximin formulation contains $\alpha$ form that has limited systemic bioavailability. However, the amorphous form was found in formulation of generic products. This does not guarantee the great tolerability of rifaximin, since the amorph form has a higher systemic bioavailability. ${ }^{[14]}$

The regulatory authorities are increasingly attentive to the polymorphisms. Generic products contain the same active principle, same dose, same pharmaceutical form, administered in the same way, in the same dosage and used for the same therapeutic indication of the reference product. This context, regulatory agencies recommended guides to contemplate trials capable of recognizing the interchangeability of branded and generic products. ${ }^{[14-16]}$

Therapeutic problems can exist in the administration of different crystalline forms of products containing rifaximin, but the problem is greater when the exchange of crystalline forms and amorphous forms happens. ${ }^{[14]}$

The polymorphism of drug depends of the synthesis, solvents used, purification and crystallization. Normally, the productive process generates a crystalline form. Studies of the literature show that the reference rifaximin has a crystalline form in the form of a hydrate and that changes in the solvents used in its process can lead to a mixture of crystalline forms and even an amorphous form. ${ }^{[14]}$

This mixture of different crystalline forms of rifaximin $(\alpha+$ $\beta, \beta, \beta+$ amorphous) and even the amorphous form have different values of potency compared to the potency of rifaximin form $\alpha$. The different combinations of rifaximin forms, $\alpha+\beta$, $\beta, \beta+$ amorphous, present melting point of approximately $217^{\circ} \mathrm{C}$. The amorphous form presents greater solubility than the form $\alpha, \beta$ and the combinations $\alpha$ and $\beta$. However, it does not have the same excellent tolerability as the reference drug, form $\alpha .^{[17,18]}$

\section{Analytical methods}

Even with all its importance, all its uses and its superiority to other drugs, rifaximin lacks of the analytical methods in the literature and in most official compendia for your quality control, because the drug's efficiency is not enough if it does not present the quality required for its safe and effective use.

Reliable and effective analytical methods are extremely important for the promotion of true and inducible results of the analyzed products. However, for this, the validation of analytical methods is necessary as it ensures the capability of the method. ${ }^{[19,20]}$

Rifaximin is not present in the investigated pharmacopoeias. ${ }^{[21-23,72]}$ The British Pharmacopoeia ${ }^{[24]}$ and European Pharmacopoeia ${ }^{[25]}$ only contemplate the monograph for rifaximin in raw material by high performance liquid chromatography (HPLC).

The pharmaceutical product of rifaximin tablets is not yet present in any official compendium, which makes the specification of the final product indefinite. This can cause damage to the quality of medicines containing rifaximin released on the market, since the chemical-pharmaceutical industries do not have a quality control parameter established in official documents.

The literature shows methods for detection of rifaximin in biological fluid as rat urine, mouse serum, human plasma and dried blood spots and milk by HPLC or high performance liquid chromatography coupled to mass spectrometry (HPLCMS). ${ }^{[10,26-32]}$

The literature also shows the detection of rifaximin in pharmaceutical product as tablets by spectrophotometry in the ultraviolet (UV), ${ }^{[33-36]}$ visible $(\mathrm{Vis})^{[37]}$ and infrared region (IR) ${ }^{[38]}$ capillary electrophoresis (CE) ${ }^{[39]}$ thin layer chromatography (TLC) ${ }^{[40]}$ high-performance thin-layer chromatographic (HPTLC) $)^{[41]} ;$ HPLC $^{[42-50]}$ and HPLC-MS. ${ }^{[40]}$

The literature also reports microbiological method for the calculation of the power of rifaximin by turbidimetry ${ }^{[44]}$ which is a more dynamic method than the traditional method by diffusion in agar. In the case of antimicrobials, the simultaneous evaluation of the material by physico-chemical and microbiological methods are extremely important. Physico-chemical methods do not always faithfully assess the potency of drugs such as antimicrobials made by the microbiological method. Care in working with these two types of techniques is fundamental to ensure quality medicines for the population. ${ }^{[51-53]}$

Dissolution method for tablets is important for the verification of dissolution profile and pharmacotechnical formula since an excellent medicine is not sufficient if it does not dissolve properly. Rifaximin presents a dissolution method with reading in spectrophotometer in the ultraviolet region. ${ }^{[54]}$

The study of the stability of raw material and pharmaceutical products is required throughout the world. The conditions used in this type of study, which includes short- and long-term stability studies, are recommended by International Conference on Harmonisation, ${ }^{[55]}$ by National Agency of Sanitary Surveillance ${ }^{[56]}$ and by guide of World Health Organization. ${ }^{[57]}$ The monitoring of drug stability helps reveal the behavior and possible product problems within the validity period. The literature shows the behavior of tablets of rifaximin during 6 months subjected to simultaneous conditions of temperature $\left(40 \pm 2^{\circ} \mathrm{C}\right)$ and humidity $(75 \pm 5 \%) .{ }^{[58]}$

All these studies are essential, especially because rifaximin can present polymorphs with characteristics and therapeutic totally different and unwanted. Analytical differences can indicate the presence of different polymorphs.

Universities have performed a fundamental role serving as research centers for the development and validation of analytical methodologies, contributing to sanitary control activities and scientific enrichment in the area. ${ }^{[59]}$

Table 1 shows the conditions of the methods for evaluation of rifaximin in biological fluids and pharmaceutical product, and Figure 2 illustrates their distribution.

The use of methods, considered green, makes unnecessary the remediation of environmental impacts often observed today ${ }^{[6,60-63,70,7,64-66]}$. Some methods for evaluation of rifaximin contemplate this thought because they use only ethanol and water, instead of methanol in the UV method, for example, or simply just potassium bromide, as shown in Table 1.

The thinking of green chemistry begins with the choice of analytical method to be used followed by apparatus and diluents. In this choice, suitability for the intended purpose must be sufficient and it cannot be based on the method that everyone uses or because it is fashionable. In a routine analysis, for example, is HPLC-MS really necessary? Is not UV or even TLC enough? Is the pre-column chromatographic necessary? 


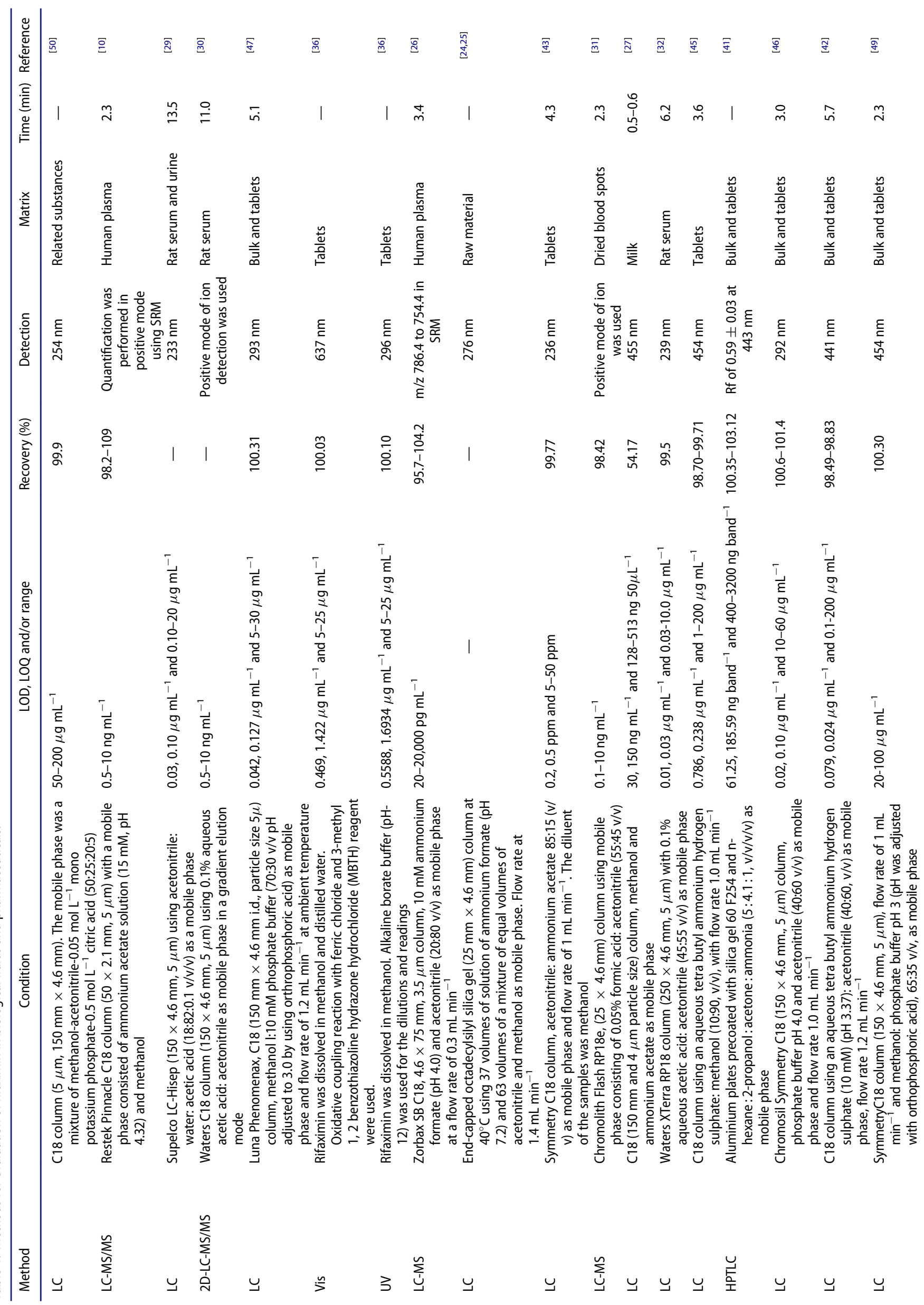




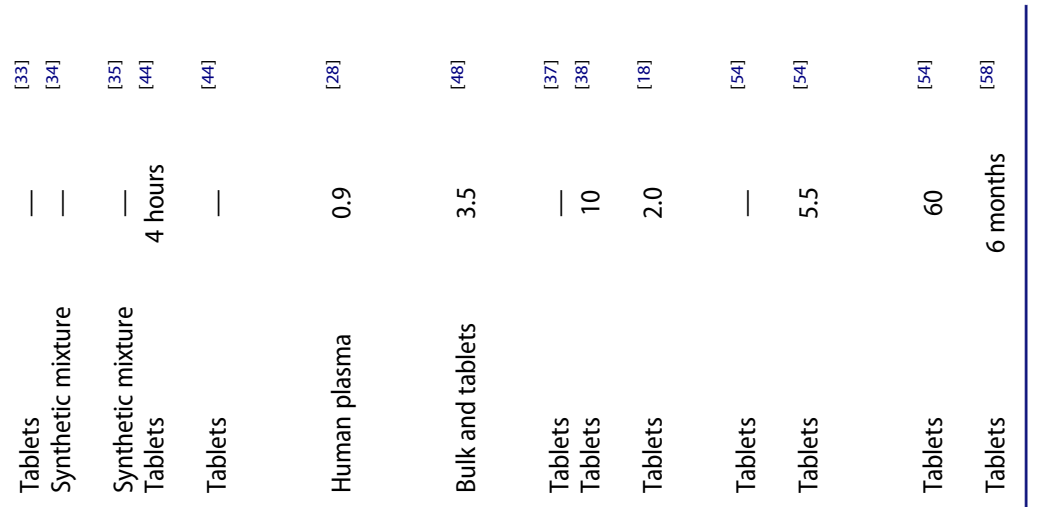

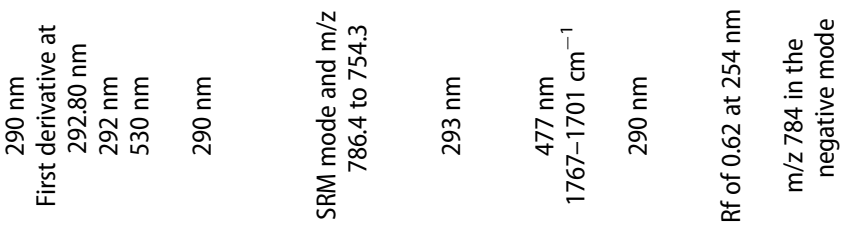

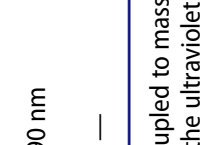

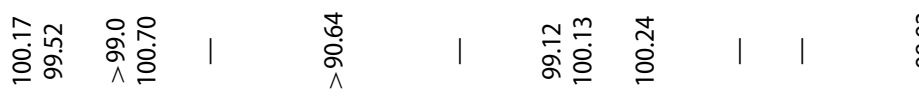

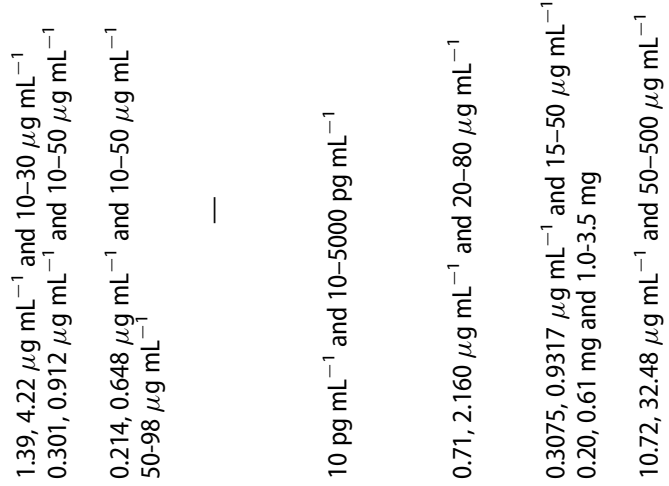

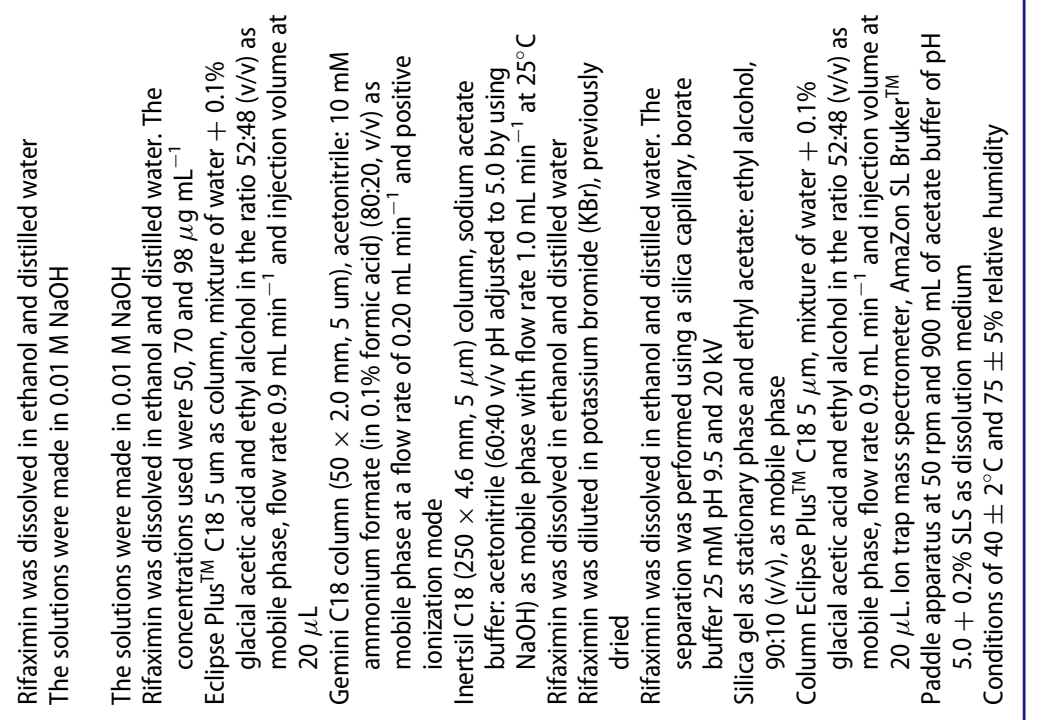

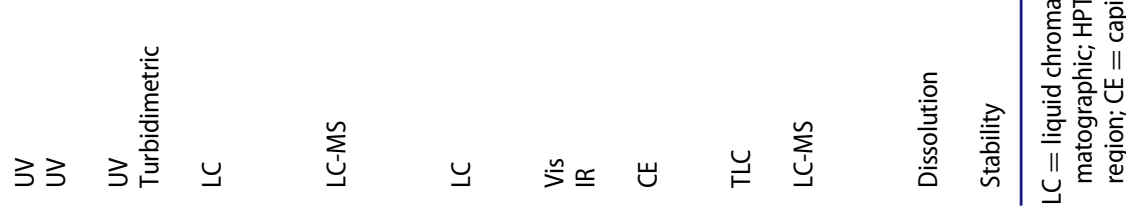



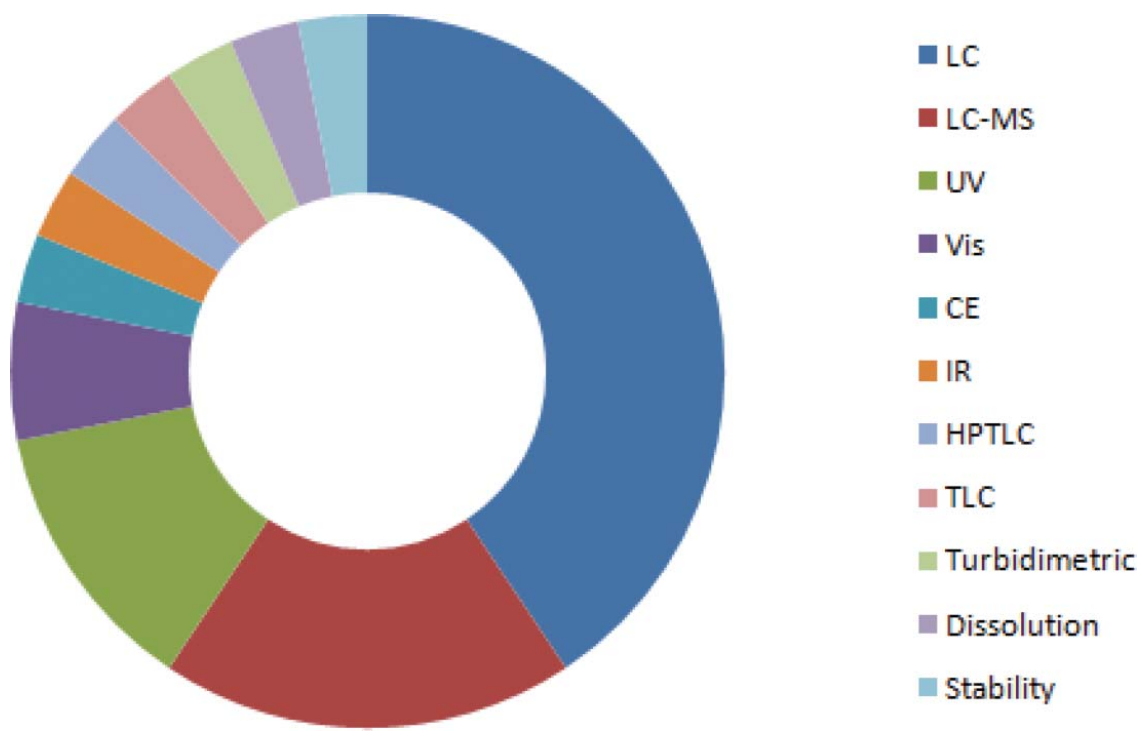

Figure 2. Current distribution of analytical methods for evaluation of rifaximin.

Buffer solutions have a short half-life and always require new preparations, which make the process more expensive. Acetonitrile, methanol and buffer solution are the diluents of choice for numerous analytical methods, but are they really needed? In the case of rifaximin, the answer is "no." Ethanol and purified water were enough.

Faster, low cost and without toxic solvents methods must be preferred for the quantification of rifaximin, focusing on the multi-dimensional impact of analytical decisions. The correct analytical choices can provide cheaper medicines on the market and more accessible to the population. This conscious and mature attitude relieves the public health system.

The use of toxic solvents such as acetonitrile and methanol, ${ }^{[67]}$ in addition to damaging the health and quality of life of the operator who is in direct and daily contact with the product, it also requires adequate waste treatment to avoid compromising the water, aquatic life, soil, plantations and animals. ${ }^{[68,69]}$

Analysts are now called upon to think about the analytical decision itself, targeting all that it impacts ${ }^{[71]}$. They must also take into consideration the development and choice of cleaner, greener, faster and lower cost methods with less steps and consumables.

Green analytical chemistry expects analysts who think beyond of the result of an analysis at any cost.

\section{Conclusion}

Rifaximin, $\alpha$ crystalline form, is an oral antimicrobial with minimal adverse effects. It is used since hepatic encephalopathy until acute diarrhea. Its wide use reaches from children to debilitated people and the evaluation of the quality of products containing rifaximina is fundamental. Thus, analytical methods are needed and currently they are seen by the look of green chemistry. Rifaximin presents in the literature options of clean, green, efficient, cheap and fast analytical methods by HPLC, UV, Vis, IR, CE and TLC. However, it still lacks a monograph in official compendium for evaluation of the final product.

\section{Conflicts of interest}

The authors declare no conflicts of interest.

\section{Acknowledgments}

The authors acknowledge CNPq (Brasília, Brazil), FAPESP (São Paulo, Brasil), CAPES (São Paulo, Brasil) and PADC/FCF/UNESP (Araraquara, Brazil).

\section{ORCID}

Ana Carolina Kogawa iD http://orcid.org/0000-0003-2834-6532

Hérida Regina Nunes Salgado (D) http://orcid.org/0000-0002-0385-340X

\section{References}

[1] Mullen, K. D.; Sanyal, A. J.; Bass, N. M.; Poordad, F. F.; Sheikh, M. Y.; Frederick, T.; Bortey, E.; Forbes, W. P. Rifaximin is Safe and Well Tolerated for Long-Term Maintenance of Remission from Overt Hepatic Encephalopathy. Clin. Gastroenterol. Hepatol. 2014, 12, 1390-1397. DOI: 10.1016/j.cgh.2013.12.021.

[2] Rivkin, A.; Gim, S. Rifaximin: New Therapeutic Indication and Future Directions. Clin. Ther. 2011, 33, 812-827. DOI:10.1016/j. clinthera.2011.06.007.

[3] Valentin, T.; Leitner, E.; Rohn, A.; Zollner-Schwetz, I.; Hoenigl, M.; Salzer, H. J. F.; Krause, R. Rifaximin Intake Leads to Emergence of Rifampin-Resistant Staphylococci. J. Infect. 2011, 62, 34-38. DOI:10.1016/j.jinf.2010.11.004.

[4] Pistiki, A.; Galani, I.; Pyleris, E.; Barbatzas, C.; Pimentel, M.; Giamarellos, Bourboulis. In vitro Activity of Rifaximin Against Isolates From Patients With Small Intestinal Bacterial Overgrowth. Int. J. Antimicrob. Agents 2014, 43, 236-241. DOI:10.1016/j.ijantimicag. 2013.12.008.

[5] Mantry, P. S.; Munsaf, S. Rifaximin for the Treatment of Hepatic Encephalopathy. Transplantation Proc. 2010, 42, 4543-4547. DOI:10.1016/j.transproceed.2010.09.173.

[6] Armenta, S.; Guardia de La, M. Green Analytical Chemistry. Trends Anal. Chem. 2008, 27, 6, 497-511. DOI:10.1016/j.trac.2008.05.003.

[7] Galuszka, A.; Migaszewski, Z.; Namiesnik, J. The 12 Principles of Green Analytical Chemistry and the Significance Mnemonic of Green Analytical Practices. Trends Anal. Chem. 2013, 50, 78-84. DOI:10.1016/j.trac.2013.04.010. 
[8] Kogawa, A. C.; Salgado, H. R. N. Comparative Study Over Methods Developed for Quantification of Darunavir in Tablets by Environmental Friendly Infrared and Capillary Electrophoretic Techniques. J. Int. Res. Med. Pharm. Sci. 2015, 2, 99-105.

[9] Kogawa, A. C; Salgado, H. R. N. Analytical Methods Need Optimization to Get Innovative and Continuous Processes for Future Pharmaceuticals. Scholars Acad. J. Pharm. 2016, 5, 6, 240-244.

[10] Zhang, X.; Duan, J.; Li, K.; Zhou, L.; Zhai, S. Sensitive Quantification of Rifaximin in Human Plasma by Liquid Chromatography-Tandem Mass Spectrometry. J. Chromatogr. B 2007, 850, 348-355. DOI:10. 1016/j.jchromb.2006.12.001.

[11] Jiang, Z.; Ke, S.; Dupont, H. L. Rifaximin - Induced Alteration of Virulence of Diarrhoea-Producing Escherichia coli and Shigella sonnei. Int. J. Antimicrob. Agents. 2010, 35, 278-281. DOI:10.1016/j. ijantimicag.2009.11.013.

[12] Ruiz, J.; Mensa, L.; ÓCallaghan, C.; Pons, M. J.; González, A.; Vila, J.; Gascón, J. In Vitro Antimicrobial Activity of Rifaximin Against Enteropathogens Causing Traveler's Diarrhea. Diagn. Microbiol. Infect. Dis. 2007, 59, 473-475. DOI:10.1016/j.diagmicrobio. 2007.07.003.

[13] Castro, R.; Domenichelli, V.; Lorenzo, F. P. L.; Prestipino, M.; Perrotta, M. L. Rifaximin Treatment for Acute Recurrent Diarrhea in Children with Genitourinary Disorders. Curr. Ther. Res. 1998, 59, 746-752. DOI:10.1016/S0011-393X(98)85034-0.

[14] Blandizzi, C.; Viscomi, G. C.; Marzo, A.; Scarpignato, C. Is Generic Rifaximin Still a Poorly Absorbed Antibiotic? A Comparison of Branded and Generic Formulations in Healthy Volunteers. Pharmacol. Res. 2014, 85, 39-44. DOI:10.1016/j.phrs.2014.05.001.

[15] Brasil. Lei ${ }^{\circ}$ 9.787, de 10 de fevereiro de 1999. Dispõe Sobre A Vigilância Sanitária, Estabelece O Medicamento Genérico, Dispõe Sobre A Utilização De Nomes Genéricos Em Produtos Farmacêuticos E Dá Outras Providências. Brasília, DF, 1999.

[16] International Conference on Harmonization. ICH Harmonized Tripartite Guideline Q6A; Rockville, MD: ICH, 1999.

[17] Kogawa, A. C.; Antonio, S. G.; Salgado, H. R. N. Characterization of Polymorphic Forms of Rifaximin. J. AOAC Int. 2016, 99, 964-971. DOI:10.5740/jaoacint.16-0053.

[18] Kogawa, A. C.; Salgado, H. R. N. Impact of Rifaximin Potency After Treatment with Different Solvents. J. Pharm. Biol. Sci. 2017a, 5, 77-80.

[19] International Conference on Harmonization. Validation of Analytical Procedures: Text and Methodology Q2(R1), Rockville, MD: ICH, 2005.

[20] La Roca, M. F.; Sobrinho, J. L. S.; Nunes, L. C. C.; Neto, P. J. R. Desenvolvimento E Validação De Método Analítico: Passo Importante Na Produção De Medicamentos. Rev. Bras. Farm. 2007, 88, 177-180.

[21] Brazilian Pharmacopeia, 5th ed.; Brasilia: ANVISA, 2010.

[22] Japonese Pharmacopeia, 16th ed.; Tokyo: Society of Japonese Pharmacopoeia, 2011.

[23] Portuguese Pharmacopeia, 9th ed.; Lisboa: Infarmed, 2010.

[24] British Pharmacopoeia. London: Her Majesty's Stationary Office, 2012.

[25] European Pharmacopoeia, 7th ed.; Strasbourg: Council of Europe, 2011.

[26] Challa, B. R.; Kotaiah, M. R.; Chandu, B. R.; Chandrasekhar, K. B.; Kanchanamala, K.; Parveen, S. K. R.; Micheal, F. HPLC Method for Determination of Rifaximin in Human Plasma Using Tandem Mass Spectrometry Detection. East Cent. Afr. J. Pharm. Sci. 2010, 13, 7884.

[27] Manjarrez, J. L. A.; Téllez, S. A.; Martínezy, R. R.; Hernández, V. O. F.; Octavio, V. Determination of Rifaximine in Milk of Dairy Cows using High Pressure Liquid Chromatography (HPLC). Rev. Cient. FCV-LUZ 2012, XXII, 112-119.

[28] Park, Y. S.; Kim, D. P.; Kim, K. T.; Park, H. C.; Kim, Y. H.; Kim, Y. N.; Kim, J. Y.; Jin, B. R.; Sim, S. J.; Lee, H. S. Validated Liquid Chromatography-Electrospray Ionization Tandem Mass Spectrometric Method for Quantification of Rifaximin Human Plasma for Pharmacokinetic Study: A Randomized, Open-Label, Two-Period, Comparative Crossover Study in Healthy Korean Male Volunteers. IOSR J. Pharm. Biol. Sci. 2016, 11, 21-28. DOI:10.9790/3008-11050298104.
[29] Rao, R. N.; Shinde, D. D.; Agawane, S. B. Rapid Determination of Rifaximin in Rat Serum and Urine by Direct Injection on to a Shielded Hidrophobic Stationary Phase by HPLC. Biomed. Chromatogr. 2009a, 23, 563-567. DOI:10.1002/bmc.1149.

[30] Rao, R. N.; Vali, R. M.; Shinde, D. D. On-Line 2D-LC-ESI/MS/MS Determination of Rifaximin in Rat Serum. Biomed. Chromatogr. 2009b, 23, 1145-1150. DOI:10.1002/bmc.1236.

[31] Rao, R. N.; Vali, R. M.; Ramachandra, B.; Maurya, P. K. Rapid Determination of Rifaximin on Dried Blood Spots by LC-ESI-MS. Biomed. Chromatogr. 2011, 25, 1201-1207. DOI:10.1002/bmc.1591.

[32] Rao, R. N.; Vali, R. M.; Rao, A. V. P. Determination of Rifaximin in Rat Serum by Ionic Liquid Based Dispersive Liquid-Liquid Microextraction Combined with RP-HPLC. J. Sep. Sci. 2012, 35, 1945-1952. DOI:10.1002/jssc.201200202.

[33] Kogawa, A. C.; Salgado, H. R. N. Quantification of Rifaximin in Tablets by Spectrophotometric Method Ecofriendly in Ultraviolet Region. Scientifica 2016, 2016, 1-9. DOI:10.1155/2016/3463405.

[34] Prajapati, K. V.; Raj, H. A.; Jain, V. C.; Prajapati, N. S. First Derivative Spectroscopic Method for Simultaneous Estimation of Mesalazine and Rifaximin in Synthetic Mixture. Pharm. Biol. Eval. 2016, 3, 231-240.

[35] Prajapati, K. V.; Raj, H. A.; Jain, V. C.; Prajapati, N. S. Simultaneous Determination of Mesalazine and Rifaximin in Synthetic Mixture Using Spectrophotometric Technique (Simultaneous Equation Method). Pharm. Biol. Eval. 2016b, 3, 199-207.

[36] Sudha, T.; Anandakumar, K.; Hemalatha, P. V.; Ravikumar, V. R.; Radhakrishnan. Spectrophotometric Estimation Methods for Rifaximin in Tablet Dosage Form. Int. J. Pharm. Pharm. Sci. 2010, 2, 43-46.

[37] Brbaklic, V.; Kogawa, A. C.; Salgado, H. R. N. Quantification of Rifaximin in Tablets by an Environmentally Friendly Visible Spectrophotometric Method. Curr. Pharm. Anal.. 2017, 13, 532-537. DOI:10.2174/1573412912666160906144024.

[38] Kogawa, A. C.; Salgado, H. R. N. Spectrophotometry in Infrared Region: A New, Low Cost and Green Way to Analyze Tablets of Rifaximin. Curr. Pharm. Anal. 2018, 14, 108-115. DOI:10.2174/ 1573412913666161213103657.

[39] Kogawa, A. C.; Schepdael, A. V.; Salgado, H. R. N. Capillary Zone Electrophoresis: A Potential and Conscious Technique for Evaluation of Rifaximin in Tablets. Curr. Pharm. Anal. 2017, submitted.

[40] Kogawa, A. C.; Mendonça, J. N.; Lopes, N. P.; Salgado, H. R. N. Method Indicative of Stability for the Determination of Rifaximin and Its Degradation Products by Thin Chromatographic. Curr. Pharm. Anal. 2017, 13, 520-524. DOI:10.2174/15734129126661 60801103712.

[41] Patel, K. G.; Jain, N. R.; Shah, P. A. Stability Indicating HPTLC Method for Analysis of Rifaximin in Pharmaceutical Formulations and an Application to Acidic Degradation Kinetic Study. ISRN Anal. Chem. 2013, 2013, Article ID 613218, 9 pages. DOI:10.1155/2013/ 613218.

[42] Annapurna, M. M.; Kumar, B. S. P.; Venkatesh, B.; Prakash, J. R Development and Validation of Stability-Indicating Liquid Chromatographic Assay for Rifaximin (An Antibiotic) in Bulk and Pharmaceutical Dosage Forms. Chem. Sci. Trans. 2014, 3, 566-575.

[43] Kasimala, B. B.; Syed, R.; Pammi, K.; Sandhya, B. RP-HPLC Method Development and Validation for the Analyisis of Rifaximin in Pharmaceutical Dosage Forms. Int. J. Res. Rev. Pharm. Appl. Sci. 2011, 1, 323-333.

[44] Kogawa, A. C.; Salgado, H. R. N. Optimization of Microbiological Method by Turbidimetry for Quantification of Rifaximin Tablets: Validation, Application and Evaluation of Degraded Compounds. Pharm. Anal. Acta 2016c, 7, 518.

[45] Narendra, A.; Annapurnab, M. M.; Kumarc, K. R. Development and Validation of the Stability Indicating Liquid Chromatographic Method for Rifaximin - An Antibiotic. J. Drug Deliv. Ther. 2013, 3, $18-25$.

[46] Rao, K. N.; Ganapaty, S.; Rao, A. L. RP-HPLC Determination of Rifaximin in Bulk Drug and Pharmaceutical Formulations. Int. J. Pharm. 2013, 3, 7-13.

[47] Sudha, T.; Hemalatha, P. V.; Ravikumar, V. R.; Jothi, R.; Radhakrishnan, M. Development and Validation of RP-HPLC Method for 
the Estimation of Rifaximin in Bulk and in Tablet Dosage form. Asian J. Pharm. Clin. Res. 2009, 2.

[48] Sumakala, S.; Vijayaraj, S.; Dharani, N. R. Development and Validation of Stability Indicating RP-HPLC Method for Estimation of Rifaximin in Bulk and Formulation. Int. J. Adv. Res. 2016, 4, 200207. DOI:10.21474/IJAR01/1473.

[49] Sunitha, P.; Mallem, A.; Kuchana, V. A. Stability Indicating Method for the Estimation of Rifaximin in its Bulk and Pharmaceutical Dosage Form by RP-HPLC Method. Int. J. Chem. Pharm. Anal. 2015, 2, 111-116.

[50] Zu-bing, Z.; Zhang-wan, L.; Xian, W.; Chang-yang, L. Determination of Rifaximin and Its Related Substances by RP-HPLC. West China J. Pharm. Sci. 2003, 4, 281-283.

[51] Kogawa, A. C.; Tomita, L. K.; Salgado, H. R. N. Development and Validation of a Stability-Indicative Turbidimetric Assay to Determine the Potency of Doxycycline Hyclate in Tablets. Int. J. Microbiol. Res. 2012, 4, 316-321. DOI:10.9735/0975-5276.4.8. 316-321.

[52] Tótoli, E. G.; Salgado, H. R. N. Development and Validation of a Rapid Turbidimetric Assay to Determine the Potency of Ampicillin Sodium in Powder for Solution for Injection. Anal. Methods 2013, 5, 5923-5928. DOI:10.1039/c3ay40847g.

[53] Tótoli, E. G.; Salgado, H. R. N. Rapid Turbidimetric Assay to Determine the Potency of Daptomycin in Lyophilized Powder. Pharmaceutics 2015, 7, 106-121. DOI:10.3390/pharmaceutics7030106.

[54] Kogawa, A. C.; Salgado, H. R. N. Evaluation of Dissolution of Rifaximin and its Importance. Eur. Chem. Bull. 2017, 6, 359-364. DOI: 10.17628/ecb.2017.6.359-364.

[55] International Conference on Harmonization. Guidance for Industry Q1a(R2) Stability Testing of New Drug Substances and Products; Rockville, MD: ICH, 2003.

[56] Agência Nacional de Vigilância Sanitária (ANVISA). RE nº 01, de 29 de julho de 2005. Guia para a realização de estudos de estabilidade. Brasília: Diário Oficial da União. 29 Jul. 2005.

[57] WHO. World Health Organization. Technical Report Series, Stability testing of active pharmaceutical ingredients and finished pharmaceutical products. Annex 2, n 953; Geneva: WHO, 2009.

[58] Kogawa, A. C.; Salgado, H. R. N. Rifaximin Stability: A Look at UV, IR, HPLC, and Turbidimetry Methods. J. AOAC Int. 2018, 101, 410-413.

[59] IFPMA. IFPA Issue Paper. Quality Assurance of Medicines. Genebra: International Federation of Pharmaceutical Manufacturers Associations, 1997.
[60] Anastas, P. T.; Kirchhoff, M. M. Origins, Current Status, and Future Challenges of Green Chemistry. Acc. Chem. Res. 2002, 35, 686-694. DOI:10.1021/ar010065m.

[61] Horváth, I. T.; Anastas, P. T. Innovations and Green Chemistry. Chem. Rev. 2007, 107, 2169-2173. DOI:10.1021/cr078380v.

[62] Keith, L. H.; Gron, L. U.; Young, J. L. Green Analytical Methodologies. Chem. Rev. 2007, 107, 2695-2708. DOI:10.1021/cr068359e.

[63] Rocha, F. R. P.; Nóbrega, J. A.; Filho, O. F. Flow Analysis Strategies to Greener Analytical Chemistry: An Overview. Green Chem. 2001, 3, 216-220. DOI:10.1039/b103187m.

[64] Marco, B. A.; Salgado, H. R. N. Characteristics, properties and analytical methods of cefadroxil: A review. Crit. Rev. Anal. Chem. 2017, 47, 93-98. DOI:10.1080/10408347.2016.1219649.

[65] Marco, B. A.; Natori, J. S. H.; Fanelli, S.; Tótoli, E. G.; Salgado, H. R N. Characteristics, Properties and Analytical Methods of Amoxicillin: A Review with Green Approach. Crit. Rev. Anal. Chem. 2017, 47, 267-277. DOI:10.1080/10408347.2017.1281097.

[66] Tobiszewski, M.; Mechlińska, A.; Zygmunt, B.; Namieśnik, J. Green analytical chemistry in sample preparation for determination of trace organic pollutants. Trends Anal. Chem. 2009, 28, 943-951. DOI: 10.1016/j.trac.2009.06.001.

[67] McElroy, C. R.; Constantinou, A.; Jones, L. C.; Summerton, L.; Clark, J. H. Towards a holistic approach to metrics for the 21st century pharmaceutical industry. Green Chem. 2015, 17, 3111-3121. DOI: 10.1039/C5GC00340G

[68] WHO. World Health Organization. International Program on Chemical Safety (IPCS), Environmental health criteria 154 - Acetonitrile, 1993. http://www.inchem.org/documents/ehc/ehc/ehc154. htm (accessed Oct 20, 2017).

[69] WHO. World Health Organization. International Program on Chemical Safety (IPCS), Environmental health criteria 196 - Methanol, 1997. http://www.inchem.org/documents/ehc/ehc/ehc196.htm (accessed Oct 20, 2017).

[70] Koel, M.; Kaljurand, M. Application of the Principles of Green Chemistry in Analytical Chemistry. Pure Appl. Chem. 2006, 78, 1993-2002. DOI:10.1351/pac200678111993.

[71] Trindade, M. T.; Kogawa, A. C.; Salgado, H. R. N. Metformin: A Review of Characteristics, Properties, Analytical Methods and Impact in the Green Chemistry. Crit. Rev. Anal. Chem. 2018, 48, 6672. DOI:10.1080/10408347.2017.1374165.

[72] USP 39. The United States Pharmacopeia, 35th ed.; Rockville: United States Convention, 2016 